Elliott, S. D. \& Barnes, Ella M. (1959). J. gen. Microbiol. 20, 426-433

\title{
Changes in Serological Type and Antibiotic Resistance of Lancefield Group D Streptococci in Chickens Receiving Dietary Chlortetracycline
}

\author{
BY S. D. ELLIOTT \\ Department of Animal Pathology, University of Cambridge \\ AND ELLA M. BARNES \\ Low Temperature Station for Research in Biochemistry and Biophysics, \\ University of Cambridge, and Department of Scientific and Industrial Research
}

\begin{abstract}
SUMMARY: The effect of dietary chlortetracycline on the serological type and resistance of the streptococci found in the caeca of chickens has been investigated. In the control birds where only chlortetracycline-sensitive streptococci were present initially, Streptococcus faecium predominated and $S$. faecalis (mainly the proteolytic variant) was present in small numbers representing three serological types (types H69D5, D15 and D76). Administration of chlortetracycline, whether at a low concentration throughout life or intermittently at a high concentration, led to the emergence of a highly-resistant non-proteolytic strain of $S$. faecalis (type H69D5) which became predominant in the antibiotic treated birds. Withdrawal of chlortetracycline was followed by disappearance of type $\mathrm{H69D5}$ and the reappearance of types D 15 and D 76 which were proteolytic. Type D 15 remained sensitive to chlortetracycline, but type D76 had become more resistant and eventually became the predominant streptococcus in all the chickens under observation. The serological types of $S$. faecalis identified in these chickens are also commonly found in the human intestine.
\end{abstract}

Barnes (1958) reported the results of a survey of the intestinal streptococci of chicken and the effect of orally administered chlortetracycline on these micro-organisms. The streptococci belonged to Streptococcus faecalis (or a proteolytic variant liquefaciens) and $\boldsymbol{S}$. faecium, two subgroups in Lancefield's group $\mathrm{D}$, distinguishable by their biochemical characteristics. These streptococci were sensitive to chlortetracycline. Inclusion of this antibiotic in the food of the chickens was followed by an increased proportion of $S$. faecalis in the intestinal bacterial flora and these streptococci were highly resistant to chlortetracycline. Withdrawal of the antibiotic was followed by disappearance of the highly-resistant non-proteolytic streptococci and their replacement by a proteolytic variant of $S$. faecalis, of resistance intermediate between that of the original population and the population established during administration of the antibiotic.

The streptococci isolated during this survey and identified as Streptococcus faecalis have now been examined serologically with the object of determining whether changes in resistance reflected changes in serological type. Throughout this report the use of the terms 'liquefaciens' and 'zymogenes' as designating the proteolytic and haemolytic variants of $S$. faecalis has been avoided. These 
properties (particularly haemolysis) are of uncertain stability and it is clear that they may vary independently of the type-specific antigens. The name $S$. faecalis as used here therefore embraces all such group D streptococci as conform to the criteria suggested for this subgroup by Skadhauge (1950) and summarized by Barnes (1956), regardless of their haemolytic and proteolytic properties.

\section{METHODS}

Full details of the rearing and feeding of the chicken, the collection and examination of caecal and faecal samples, identification of the faecal streptococci and tests for their antibiotic resistance were given by Barnes (1958). Cultures classified as Streptococcus faecalis were further examined by using the methods described by Barnes, Ingram \& Ingram (1956); their proteolytic properties were tested by their ability to liquefy gelatin.

\section{The serological typing of group $D$ streptococci}

Lancefield (1941) identified three serological types among her group D streptococci and has since added one further type (personal communication); the type-specific antigens were thought to be polysaccharides. Sharpe \& Shattock (1952) differentiated nine serological types, including Lancefield's original three types, among streptococci classified by them as Streptococcus faecalis; the type-specific antigens were not characterized chemically but were recognized by agglutination and precipitation reactions. In the work to be described here the serological types of $S$. faecalis were characterized antigenically by their cell-wall polysaccharides. Evidence that in group D streptococci the type-specific polysaccharides are an integral part of the bacterial cell wall will be presented by one of us (S.D.E.) later. They can be extracted from the streptococci either by tryptic digestion or by treatment with hot acid, and identified by precipitin tests with hyperimmune rabbit serum of homologous type. The immunization of rabbits with formalin-killed group D streptococci commonly leads to the production of type-specific antibody but little, if any group-specific antibody. Serum taken from rabbits in the early stages of immunization often gives only type-specific precipitation reactions especially when, as is the case with tryptic digests, the bacterial extracts contain minimal amounts of group antigen. In the present work, the 'typing' of streptococci was accomplished by precipitin tests with tryptic digests and with acid extracts as the source of type-specific antigen. The antigen preparations were tested first against crude antisera and positive reactions subsequently confirmed with type-specific sera from which group antibody had been removed by absorption with strains of heterologous type.

Preparation of type-specific antisera. Type-specific precipitating antisera were prepared in rabbits against Lancefield's 4 group D 'type' strains (strains D76, H69D5, C1, C3) and also against two strains of Streptococcus faecalis (D10 and D15) isolated by Evans (1957) from cases of bovine endocarditis and later shown to be distinct serological types in group D (Elliott, 1957). Strain C3 belongs to $S$. durans; strains D76, H69D5, C1 and D15 belong to 
S. faecalis and correspond to types 1, 3, 4, and 9 in the classification of Sharpe \& Shattock (1952).

Vaccines were prepared from streptoccci grown in Todd-Hewitt broth at room temperature for $18 \mathrm{hr}$. and killed by the addition of formaldehyde (final concentration $2 \%, w / v$ ). After 2-3 days the cocci were washed and resuspended in saline. Procedures for the immunization of rabbits and absorption of antisera were those recommended by Lancefield (1938, 1940). For absorbing non-specific antibody from group D typing sera Lancefield's strain C1 was generally used. Most sera required several absorptions before they became type specific and in some instances those strains which gave persistent cross-reactions were used for the final absorption.

Preparation of streptococcal extracts. (i) Tryptic digestion. Cultures were grown in $40 \mathrm{ml}$. amounts of Todd-Hewitt broth for $18 \mathrm{hr}$. at room temperature. Formaldehyde was then added (final concentration $2 \%, \mathrm{w} / \mathrm{v}$ ) and the cultures left at room temperature for $24-48 \mathrm{hr}$. The streptococci were then washed, first in saline and then in $\mathrm{m} / \mathbf{3 0}$ phosphate buffer ( $\mathrm{pH} 8$ ). Finally, they were suspended in $0.5 \mathrm{ml}$. phosphate buffer $(\mathrm{pH} 8$ ) containing crystalline trypsin $0.1 \mathrm{mg} . / \mathrm{ml}$. and incubated for $1 \mathrm{hr}$. at $37^{\circ}$. After this digestion, the supernatant fluid contained mainly type antigen and little, if any, group-specific antigen and was used in precipitation reactions without further treatment. (ii) Acid extraction. The method of Lancefield (1940) was used. Streptococci from $40 \mathrm{ml}$. cultures which had first been subjected to tryptic digestion (see above) were subsequently resuspended in a volume of $0.5 \mathrm{ml}$. and heated at $100^{\circ}$ and c. $\mathrm{pH} 2$ for $10 \mathrm{~min}$. Extracts prepared by this method contained type and group antigens.

Immunological reactions. The precipitin test by the capillary technique was used (Swift, Wilson \& Lancefield, 1943). Capillary tubes (internal diam. $1.0 \mathrm{~mm}$.) were used and the 'typing' sera were such that positive reactions could be read within $15 \mathrm{~min}$. at room temperature.

\section{RESULTS}

Effect of a dietary supplement of chlortetracycline on Streptococcus faecalis in the intestine of chickens

The design of this experiment was described by Barnes (1958). Three groups of chickens were reared under conditions which were identical except that two groups received a dietary supplement of chlortetracycline: one group received the control ration with a constant supplement of chlortetracycline at 25 p.p.m.; the other received an intermittent supplement at 400 p.p.m. At the end of 12 weeks, 12 birds in each group were killed and the relative numbers of Streptococcus faecalis and $S$. faecium in their caeca determined. In 9 of the control birds and 8 of those which received chlortetracycline a more detailed bacteriological examination was made. From the control birds 19 colonies of $S$. faecalis (1 to 4 from each bird), and from the birds which received chlortetracycline 53 colonies ( 5 to 10 from each), were serologically typed. The results are shown in Table 1. 
It will be seen that in the control birds Streptococcus faecium was the predominant streptococcus. S. faecalis was present only in very small numbers; indeed, it was difficult to obtain a sufficient number of colonies for further bacteriological examination. None of these streptococci were able to grow on nutrient agar + chlortetracycline at 10 p.p.m. Extracts prepared from 17 strains of $S$. faecium (from 8 birds) failed to react with any of the five $S$. faecalis typing sera available, three of which, corresponding to types D76, D15 and H69D 5, were sufficient to identify all 19 cultures of $S$. faecalis isolated from the control birds. Of the 13 control cultures belonging to type Dr6 or to D15, all were proteolytic, whereas of 6 belonging to type H69D5, 2 were proteolytic and 4 non-proteolytic.

\section{Table 1. Effect of dietary chlortetracycline on faecal streptococci in the caeca of chickens at 12 weeks \\ No. of birds with $S$. faecalis of specified serological type, CTC* resistance and proteolytic activity

\begin{tabular}{|c|c|c|c|c|c|c|c|}
\hline \multirow[b]{3}{*}{ Diet } & \multirow{3}{*}{$\begin{array}{l}\text { Approx. } \\
\text { ratio: } \\
\text { S. faecalis }\end{array}$} & \multirow{3}{*}{$\begin{array}{l}\text { No. of } \\
\text { birds (or } \\
\text { colonies) } \\
\text { examined } \\
\text { in detail }\end{array}$} & \multicolumn{5}{|c|}{$\begin{array}{l}\text { No. of birds with } S . \text { faecalis of specified serological } \\
\text { type, CTC* resistance and proteolytic activity }\end{array}$} \\
\hline & & & \multicolumn{3}{|c|}{ Proteolytic } & \multicolumn{2}{|c|}{ Non-proteolytic } \\
\hline & & & $\begin{array}{c}\text { Type } \\
\text { Dr6 } \\
\text { sensitive }\end{array}$ & $\begin{array}{c}\text { Type } \\
\text { D15 } \\
\text { sensitive }\end{array}$ & $\begin{array}{c}\text { Type } \\
\text { H69D5 } \\
\text { sensitive }\end{array}$ & $\begin{array}{c}\text { Type } \\
\text { H69D5 } \\
\text { sensitive }\end{array}$ & $\begin{array}{c}\text { Type } \\
\text { H69D5 } \\
\text { resistant } \dagger\end{array}$ \\
\hline Control & 0.001 & $9(19)$ & $1(2)$ & $5(11)$ & $1(2)$ & $4(4)$ & - \\
\hline $\begin{array}{l}\text { Continuous } \\
\text { CTC sup- } \\
\text { plement } \\
25 \text { p.p.m. }\end{array}$ & $1 \cdot 0$ & $6(38)$ & 一 & - & - & 一 & $6(38)$ \\
\hline $\begin{array}{l}\text { Intermit- } \\
\text { tent CTC } \\
\text { supplement } \\
40 \text { p.p.m. }\end{array}$ & $\begin{array}{r}100 \\
t \quad\end{array}$ & $2(15)$ & - & - & - & - & $2(15)$ \\
\hline \multicolumn{8}{|c|}{$\begin{array}{l}\text { () }=\text { Number of colonies examined. } \\
* \text { CTC }=\text { Chlortetracycline. } \\
+ \text { Sensitive }=\text { failed to grow on agar containing CTC } 10 \text { p.p.m. } \\
+ \text { Resistant }=\text { grew on agar containing CTC } 200 \text { p.p.m. }\end{array}$} \\
\hline
\end{tabular}

The caecal cultures from the two groups of birds which received the chlortetracycline supplement were in striking contrast to those from the control group. In the birds which received the small but continuous supplement (25 p.p.m.) the numbers of Streptococcus faecalis and $S$. faecium were approximately equal, while in those birds given the larger intermittent supplement (400 p.p.m.), S. faecalis was predominant. All cultures of $S$. faecalis isolated from either group grew on nutrient agar + chlortetracycline at 200 p.p.m.; all were non-proteolytic; and all belonged to one serological type, type H69 D 5. It is noteworthy that non-proteolytic type $\mathrm{H69D} 5$ streptococci were present in four of the control birds but these were not able to grow on nutrient agar + chlortetracycline at 10 p.p.m. By using the serial dilution technique with Difco Penassay broth containing chlortetracycline it was confirmed that the type H69D5 cultures isolated from the birds fed chlortetracycline were about 200 times more resistant than those of the same serotype recovered from 
control birds. From the results of this experiment it was concluded that oral administration of chlortetracycline led to the development of a resistant variant of $S$. faecalis type $\mathrm{H} 69 \mathrm{D} 5$. This variant may have appeared originally in one bird only or simultaneously in two or more but, through selective proliferation in the presence of the antibiotic, it supplanted most of the other streptococci in the intestines of those chickens receiving chlortetracycline.

\section{Effect of withdrawing the chlortetracycline dietary supplement on Streptococcus faecalis in the intestinal tract of chickens}

The effect of withdrawing chlortetracycline from the diet was tested on those birds which had previously received the larger supplement (400 p.p.m.), since they showed the greatest difference in streptococcal population from the control group. The 38 surviving birds (12 weeks old) in both the control and chlortetracycline groups were given the same diet (without antibiotic) during 5 months. At the end of 3 months bulk samples of intestinal dejecta from each group were examined. After a further 2 months, i.e. 5 months after discontinuing the antibiotic supplement, three birds from the group originally given chlortetracycline and two from the control group were killed. Bacteriological examinations of the caecal contents were made as before and colonies of Streptococcus faecalis isolated for further study.

Table 2. Change in faecal streptococci in chickens following withdrawal of a dietary supplement of chlortetracycline at 12 weeks of age

No. of colonies of specified serological type

\begin{tabular}{|c|c|c|c|c|c|c|}
\hline \multirow[b]{3}{*}{$\begin{array}{c}\text { Age at } \\
\text { sampling }\end{array}$} & \multirow{3}{*}{$\begin{array}{l}\text { Source of } \\
\text { sample } \\
\text { and no. } \\
\text { of birds } \\
\text { examined }\end{array}$} & \multirow{3}{*}{$\begin{array}{c}\begin{array}{c}\text { Approx. } \\
\text { ratio } \\
\text { S. faecalis }\end{array} \\
\text { S. faecium }\end{array}$} & \multirow{3}{*}{$\begin{array}{c}\text { No. of } \\
\text { colonies } \\
\text { of } S . \text { faecalis } \\
\text { examined } \\
\text { in detail }\end{array}$} & \\
\hline & & & & \multicolumn{2}{|c|}{ Proteolytic } & \multirow{2}{*}{$\begin{array}{c}\text { Non- } \\
\text { proteolytic } \\
\text { Type H69D5 } \\
\text { resistant }\end{array}$} \\
\hline & & & & $\begin{array}{l}\text { Type D } 15 \\
\text { sensitive* }\end{array}$ & $\begin{array}{l}\text { Type D76 } \\
\text { resistant } \dagger\end{array}$ & \\
\hline 12 weeks & Caeca, 2 birds & 100 & 15 & - & - & 15 \\
\hline 6 months & $\begin{array}{l}\text { Bulk faecal } \\
\text { samples, } \\
38 \text { birds }\end{array}$ & $10(100)$ & $24(6)$ & 21 & $3(4)$ & - \\
\hline 8 months & Caeca, 3 birds & $5(10)$ & $25(28)$ & $\mathbf{1}$ & $24(28)$ & 一 \\
\hline
\end{tabular}

( ) = Corresponding data from control birds which had never received chlortetracycline (CTC).

* Sensitive $=$ failed to grow on agar containing CTC 10 p.p.m.

$\uparrow$ Resistant $=$ grew on agar containing CTC 50 p.p.m.

$\ddagger$ Resistant $=$ grew on agar containing CTC 200 p.p.m.

The results of these surveys are shown in Table 2 . It will be seen that in the 6 months old birds i.e. 3 months after discontinuing the antibiotic supplement, Streptococcus faecalis outnumbered $S$. faecium in the dejecta of control and of previously antibiotic-fed birds. Type H69D5 streptococci were not found in either group, but a chlortetracycline-resistant proteolytic strain of type D76 appeared in both. Type D15, previously found in the control group and presumably present (although not demonstrated) in the antibiotic treated birds, had now reappeared in the latter and remained sensitive to chlor- 
tetracycline. Two months later, i.e. 5 months after discontinuing the antibiotic supplement, the chlortetracycline-resistant type D76 had become established as the predominant streptococcus in the intestinal tract of all the birds examined. Type D15, sensitive to chlortetracycline, was still present in at least one chicken, but the type H69D5 streptococcus was not found in any.

\section{DISCUSSION}

Of the 155 cultures of Streptococcus faecalis examined in the course of this investigation all except two were identified as belonging to one or other of three distinct serological types. It is of interest that we have also identified these types among streptococci isolated from adult human intestinal tracts; the same types were found by Sharpe \& Shattock (1952) in infants with neonatal diarrhoea. The small number of types represented in the present study might be thought to detract from the validity of conclusions based on the assumption that organisms belonging to the same type represent a single strain and had a common origin. For example, it might be doubted whether the type D15 streptococci encountered in birds from whose diet chlortetracycline had been withdrawn were the direct descendants of streptococci of the same type encountered in controls and presumably present, although not demonstrated, in all birds before administration of the antibiotic. It will be recalled that during the intervening period, i.e. during administration of chlortetracycline, type D15 disappeared and its place was taken by type H69D 5. Similarly, in the absence of additional evidence, it could be open to question whether the chlortetracycline-resistant type H69D5 streptococci were developed from the sensitive micro-organisms of this type present before administration of the antibiotic. Our belief that such was the case is strengthened by the existence of independent 'strain markers' characterizing these streptococci of type D15 and type H69D5. All of the cultures identified as type D15 were haemolytic when grown on horse blood agar and, apart from these cultures, no other haemolytic strain was encountered during this investigation. Non-haemolytic strains of type D15 had previously been found in other birds in the same locality. Similarly, all but two of the cultures identified as type $\mathrm{H} 69 \mathrm{D} 5$ were non-proteolytic and these were the only non-proteolytic cultures of $\boldsymbol{S}$. faecalis isolated from the control birds. Indeed, non-proteolytic strains of $S$. faecalis are rarely met with in the intestinal tract of chickens fed on a normal diet.

It is our impression that under the conditions of antibiotic feeding imposed in this experiment, chlortetracycline-sensitive streptococci originally present in the intestinal tract of the chickens were suppressed but not completely eliminated. Their place was taken by a strain of Streptococcus faecalis type H69 D 5 which rapidly developed resistance to the antibiotic. That this resistant strain was non-proteolytic may have been fortuitous. Alternatively, it is possible that resistance to chlortetracycline is more readily developed by non-proteolytic than by proteolytic streptococci of this type, for it will be recalled that both proteolytic and non-proteolytic chlortetracycline-sensitive 
type $\mathrm{H} 69 \mathrm{D} 5$ streptococci were present in the control birds at the beginning of the experiment. Supporting this hypothesis were the results of an in vitro experiment in which the sensitive proteolytic and non-proteolytic type H69 D5 streptococci were serially subcultivated in broth containing increasing concentrations of chlortetracycline. Under these conditions the resistance of the non-proteolytic variant increased 32-fold while that of the proteolytic variant increased only eightfold. With both cultures considerable difficulty was experienced in further increasing their resistance.

It is of interest that from the birds fed throughout life with a 25 p.p.m. chlortetracycline supplement and from those which received an intermittent 400 p.p.m. supplement an identical highly resistant type H69D5 streptococcus was isolated. The two groups of birds differed in that, although the total number of faecal streptococci was approximately the same in both, in the group which received the larger supplement type $\mathrm{H} 69 \mathrm{D} 5$ streptococci markedly outnumbered Streptococcus faecium whereas in the birds given the smaller supplement, type H69D5 and $S$. faecium were present in equal numbers. It may well be that the wide distribution of the resistant type $\mathrm{H} 69 \mathrm{D} 5$ streptococcus in the birds which received chlortetracycline was due to cross infection. The degree to which this micro-organisms outnumbered the less resistant faecal streptococci clearly depended, in part, upon the concentration of the antibiotic in the intestines.

Following withdrawal of the antibiotic, conditions in the intestinal tract reverted to normal and presumably became more favourable for the proliferation of proteolytic than for non-proteolytic streptococci, for the former promptly regained the ascendancy and the non-proteolytic chlortetracyclineresistant strain disappeared. Finally, a single proteolytic strain, type D76, which had developed some degree of resistance to chlortetracycline, became established as the predominant representative of Streptococcus faecalis in the intestinal tract of control chicken and of those previously fed the antibiotic. The reason for the final ascendancy of this particular strain is not clear. Its resistance to chlortetracycline would hardly be advantageous in the absence of the antibiotic; R. F. Gordon \& J. F. Tucker (personal communication) also found a significant proportion of resistant coliforms in these chickens 5 months after the antibiotic supplement was withdrawn.

We are indebted to Dr R. C. Lancefield for type-specific antisera corresponding to her 4 group D 'type' strains. The contribution of E.M.B. to this paper was as part of the programme of the Food Investigation Organization of the Department of Scientific and Industrial Research.

\section{REFERENCES}

Barnes, E. M. (1956). Tetrazolium reduction as a means of differentiating Streptococcus faecalis from Streptococcus faecium. J. gen. Microbiol. 14, 57.

Barnes, E. Mn (1958). The effect of antibiotic supplements on the faecal streptococci (Lancefield group D) of poultry. Brit. vet. J. 114, 333.

Barnes, E. M., Ingram, M. \& Ingram, G. C. (1956). The distribution and significance of different species of faecal streptococci in bacon factories. J. appl. Bact. 19, 204. 
Eluiott, S. D. (1957). Bacterial endocarditis of cattle. Vet. Rec. 69, 1203.

Evans, E. T. Rees (1957). Bacterial endocarditis of cattle. Vet. Rec. 69, 1190.

LANCEFIELd, R. C. (1938). A micro precipitin technique for classifying haemolytic streptococci and improved methods for producing antisera. Proc. Soc. exp. Biol., N.Y. 38, 473.

Lancefield, R. C. (1940). Type-specific antigens, $M$ and $T$ of matt and glossy variants of group A haemolytic streptococci. J. exp. Med. 71, 521.

LANCEFIELD, R. C. (1941). Specific relationship of cell composition to biological activity of haemolytic streptococci. Harvey Lect. Series 36, 251.

Sharpe, M. E. \& Shattock, P. M. F. (1952). The serological typing of group D streptococci associated with outbreaks of neonatal diarrhoea. J. gen. Microbiol. 6, 150 .

Skadhauge, K. (1950). Studies on Enterococci weith Special Reference to the Serological Properties. Copenhagen: Einar Munksgaard.

Swift, H. F., Wilson, A. T. \& Lancefield, R. C. (1943). Typing group A haemolytic streptococci by $\mathrm{M}$ precipitin reactions in capillary pipettes. J. exp. Med. 78, $12 \%$.

(Received 11 November 1958) 